\title{
Expectations about Monetary Policy and the Behaviour of the Central Bank*
}

\author{
Bernardo Dutra ${ }^{* *}$
}

\begin{abstract}
Using microdata from the IBRE-FGV Consumer Survey we investigate if Brazilian consumers form expectations consistent with the Taylor rule and if the consistency changes according to the monetary policy conducted by the Central Bank of Brazil. We find that the public can properly understand the relationship between interest rates and inflation in the rule framework, but not the relationship between interest rates and unemployment, probably due to the single mandate adopted in Brazil and some features of the data. The partial effects methodology introduced by Carvalho and Nechio (2014) confirm these results. Furthermore, we also find that the consistency of expectations significantly drops during periods that the central bank deviates from the Taylor rule, indicating that a higher tolerance to inflationary shocks can damage the coordination of society's expectations.
\end{abstract}

Keywords: Consumer expectations; Monetary Policy; Taylor rule.

JEL codes: D84, E52, E58.

Submitted in 21/08/2015. Revised in 17/07/2017.

I thank Bernardo Guimarães, Carlos Carvalho, Vladimir Teles, Thiago Curado, Raone Costa and the anonymous referees for helpful comments. I also thank IBRE-FGV and, especially, Viviane Bittencourt for the data. I gratefully acknowledges financial support from CAPES.

** Sao Paulo School of Economics - FGV. Email: btdutra@gmail.com. 


\section{Introduction}

The anchoring of expectations has a fundamental role for monetary policy efficiency. Individual's expectations about macroeconomic variables affect consumption and savings decisions and thus influence price and salary dynamics in the economy. For this reason, central banks have intensified their concerns with more clear and transparent communication aiming towards a better understanding of their decisions and the coordination of people's expectations.

In this paper we examine if people understand the monetary policy pursued by the Central Bank of Brazil (BCB). Based on survey data from the Survey of Consumers of the Getulio Vargas Foundation (IBRE-FGV), which contains consumer forecasts about the Brazilian economy, we measure the consistency degree of expectations about the Taylor rule and its evolution between 2005 and 2013.

As a result, we find that the Brazilian consumer can perceive the right relationship between interest rates and inflation within the rule's framework, but the same is not true for the relationship between interest rates and unemployment. However, this second case does not necessarily represents a misunderstanding, because the unemployment rate didn't varied in a cyclical manner during the period and also because of lessor attention given to this variable in the strict inflation targeting regime pursued by the BCB. In a similar analysis, Carvalho and Nechio (2014) test if the American consumer understands the basic principles underlying the Taylor rule using a reduced form non-parametric approach. The application of their methodology for the Brazilian consumer lead to the same results described above.

Ideally, a coherent central bank would have more facility in promoting an environment with anchored expectations where shocks to the economy would dissipate in the long run, but conduct deviations would affect agents understanding. We also show evidence that consumer understanding about the monetary policy has changed during the 2011 easing cycle, probably because of the monetary policy shift to a more dovish stance.

In comparison to the work of Carvalho and Nechio (2014), this paper is more focused on the consistency of expectations according to the monetary policy conduction in Brazil, with an additional motivation that the $\mathrm{BCB}$ was more dovish than the Federal Reserve during the period considered. Thus, our results lead to 
evidence that central bank deviations on that period could have contributed to their recent loss of credibility.

Winning credibility requires a more transparent and informative communication strategy about monetary policy decisions. Despite no consensus regarding an optimal communication strategy, the improving of communication pursued by several central banks around the world has been fostering positive effects like more predictability, less market volatility, and a more stable inflation environment (Blinder et al.,2008). However, more attention has been given to financial market agents.

This paper attempts to give more focus to consumer expectations. Besides the important role they played in price determinacy on the economy, they politically legitimize the autonomy of the central bank through the democratic process. More transparency, thus, reflects the compromise with accountability (Yellen, 2015). Therefore, our approach also is an important evaluation of BCB's communication and credibility accomplishment with the people.

Our analysis assumes the Taylor rule as the usual monetary policy framework implemented by the central banks. The adoption of a monetary policy rule based on a target for the policy rate became a standard practice after the seminal work of Taylor (1993) that specifies the interest rate as a function of price and activity variations. To understand this relationship in a dual mandate context ${ }^{1}$ means to be consistent with the Taylor rule, definition that will be discussed more carefully throughout the paper. However, it's important to consider that this vision has some limitations because monetary policy decisions depend on many other factors besides the current inflation and the output gap, as specified by the simple Taylor rule (Svensson, 2003).

In Brazil it's adopted the strict inflation targeting regime, implemented in 1999. Since then, this regime has contributed to price stability, because in spite of some inflationary shocks in the period, inflation remained constantly within the target limits. ${ }^{2}$ However, some conduct deviations of the BCB has been noted in the period.

1 Some countries adopted the inflation targeting regime, where the monetary authority's main objective is to secure the purchasing power of the currency, which would be considered as a single mandate, or strict inflation targeting. After the crisis, the financial stability objective has also become relevant, characterizing a kind of "triple" mandate. These cases can be considered as variations of the basic formulation of the rule introduced by Taylor (1993). 
Balbino, Colla and Teles (2011) show that between 1999 and 2009 the monetary policy adopted by the central bank behaved homogeneously among the different managements in terms of response to inflation and output shocks, but with different degrees of hawkishness if we take into account exogenous inflation shocks in the period. Similarly, Moreira, Souza and Ellery Jr. (2013) verified that there were changes in BCB tolerance to inflationary shocks between the three managements after 2001 .

In the usual framework of recent macroeconomic models expectations have a direct effect on the results of economic policy. The equilibrium between firms and consumers, as determined by the basic new Keynesian model, expectations about the future of prices and output are taken as inputs by the central banker. With anchored expectations, the policy transmission mechanism becomes more effective and the central bank has greater facility in promoting economic stability.

In practice, central bankers have already shown their concern about consumer expectations on a number of occasions. In a speech at The Economic Club of New York, Richard Fisher, former Dallas Fed president, observed: "First, in this era of social media and über-transparency, we at the Fed need to learn to speak English, rather than "Fedspeak". I have done my level best during my tenure at the Fed to speak plainly, always bearing in mind that when I speak as a Fed official, I am speaking to the American people whom we serve, not to a small group of economists or just to the mavens of Wall Street". ${ }^{3}$ That's not different in Brazil. In his inaugural speech, Alexandre Tombini said: "Adopted more than 11 years ago, the inflation targeting regime has unquestionable success in achieving its main goal of coordinating society's expectations..." (Tombini, 2011).

For a number of years the monetary policy expectations literature has expanded and started to cover different issues, but little attention has been given to the consumers. The poor predictive power of households about macroeconomic variables, due to information rigidity and rational inattention, as well as the greater concern with the expectations of price and wage-setters agents are possible explanations.

2 From 1999 to 2013 annual inflation was outside the upper and lower bounds of the inflation target on three occasions: 2001, 2002 and 2003.

3 http://www.dallasfed.org/news/speeches/fisher/2015/fs150210.cfm 
On the one hand, some studies focused more attention on financial market analysts. Mitchell and Pearce (2009) and Carvalho and Minella (2012) investigate the predictive power of economists and market professionals about interest rates, inflation and output as well as the consistency of expectations with the Taylor rule using the Wall Street Journal's semiannual survey of professional Economists and BCB's Focus Survey, respectively.

Carroll (2003) proposes a model in which agents update their expectations with a certain probability based on financial market forecasts released in the media. The reason for this is the assumption that consumers rationally believe that market professionals make much more accurate forecasts, but update their expectations only occasionally when they read newspapers. Thus, the model is able to explain several features of the data that rational expectations models cannot.

Another part of the literature focused on consumer expectations about specific macroeconomic variables. Mankiw et al. (2004) demonstrate that agents disagree with each other about expected future inflation and this can be translated by a simple "sticky-information" model. Souleles (2004) discusses the main characteristics of American consumer forecasts about different macro variables.

Coibion and Gorodnichenko (2012) show that information rigidity affects agents' forecasts about the economy and causes delays in the response of expectations to shocks. For this reason, the authors emphasize that informational frictions should be incorporated into macroeconomic models. In turn, Preston (2006) focuses attention on the importance of private agents' forecasts for monetary policy design. According to the author, if the central bank does not correctly understand the learning mechanism of private agents, the usual rules of monetary policy based on expectations can lead to divergences of learning and thereby create obstacles to the stability of economic fluctuations.

As mentioned earlier, our work is more related to the literature that uses survey data to measure the consistency of expectations about macroeconomic concepts, as Carvalho and Nechio (2014) for the United States. Drager et al. (2013) extend the approach using the Michigan Survey to check if the American consumer comprehends the basic principles of the Phillips Curve and the Fisher's Equation. 
The remainder of the paper is structured as follows. Section 2 describes the Consumer Survey data used to analyze consumer forecasts for selected macroeconomic variables. Section 3 introduces the analysis of consistency of expectations and the empirical method used to evaluate the public's understanding about monetary policy. Next, Section 4 assesses consumer expectations according to the behavior of the central bank in the period. The last section concludes.

\section{Data}

The Consumer Survey is a monthly survey conducted by IBRE-FGV since 2005 that aims to generate confidence indicators of the Brazilian consumer about the economy. Each month an independent and representative sample of the Brazilian population is selected with about 2 thousand consumers, in which some are interviewed repeatedly, setting up a rotating and unbalanced panel. ${ }^{4}$ Our sample contains microdata with consumer forecasts in the period between September 2005 and December 2013.

The survey has 29 questions on topics such as business conditions, labor market, investment decisions, among others. In addition, the answers also classify individuals according to sex, age, income and education, which allows for analyzing the heterogeneity of responses according to sociodemographic characteristics. We will focus on three specific questions, first on the variation of employment:

"In the next six months, getting a job will be: much easier, a little easier, equal, a little harder or a lot harder?"

On the numerical forecast of inflation:

"In your opinion, how much will Brazilian inflation be in the next 12 months? $A$ : $\% "$

About the interest rate variation:

"In your opinion, in the next six months the interest rate will go up, stay the same or fall?"

We will use the unemployment rate, therefore, as a proxy for the output, because it is the question that best represents expectations about economic activity. On inflation, it seems reasonable to assume that the consumer makes forecasts based

4 More specifically, a sample of 2,045 consumers was defined in order to obtain an absolute sampling error of $2.19 \%$ and a $95 \%$ confidence interval. For more information: http: //portalibre.fgv.br/main.jsp?lumChannelId=402880811D8E34B9011D92BB7A891DEF 
on the National Broad Consumer Price Index (IPCA), the indicator used for the inflation target.

Regarding the interest rate question, we are assuming an association with the Selic rate used by the $\mathrm{BCB}$ as the monetary policy instrument. One can argue that consumers are more sensitive to credit rates, but we observe that the banking spread, calculated using the Selic as the funding rate and the non-earmarked consumer credit rates of the $\mathrm{BCB}^{5}$, remained fairly constant in the period of interest, despite a slight downward trend. ${ }^{6}$

As already mentioned, we are not interested in evaluating the quality of people's forecasts, since a non-specialist is not always willing to incur the costs of acquiring information about the economic situation, a phenomenon also known as rational inattention, and therefore estimates of specific variables become imprecise. Thus, our analysis focuses on the direction of forecasts, and for this reason we will construct a categorical variable for inflation expectations that symbolizes increase, maintenance or fall. One can also suppose that the individual applies some rounding procedure when answering about the expected direction of a certain variable. We then construct approximation intervals of 0.2 and 0.5 percentage points in the construction of the categorical variable. That is, if the difference between forecasted and real inflation is within the range $(-0.2,0.2)$ or $(-0.5,0.5)$, in percentage points, we consider that the household is forecasting no change in the variable.

Table 1 shows frequency directions for each variable from the Survey's forecasts and realized data. The data shows that the period from 2005 to 2013 was characterized by a greater proportion of interest rate and unemployment declines and increases in inflation, even with rounding. However, households' forecasts in the Survey only seem to correctly predict the price increases. ${ }^{7}$

5 Alternatively, the spread series provided by the World Bank from 2005 to 2012, which is is the interest rate charged by banks on loans to private sector customers minus the interest rate paid by commercial or similar banks for demand, time, or savings deposits, also does not vary widely.

6 However, it is important to note that despite the constant spread, the different interest rates in the market to which each individual is exposed adds an idiosyncratic noise to this analysis, which may disrupt the estimates.

7 Another limitation in the analysis is the different horizons of forecasting in the questions, since the inflation forecast is for 12 months, while the others are for 6 months. We assume that consumers do not differentiate and consider both cases as the future of the variables. 
Table 1

Forecats frequencies and realized data

\begin{tabular}{lccccccc}
\hline & \multicolumn{3}{c}{ Survey } & & \multicolumn{3}{c}{ Data } \\
\cline { 2 - 4 } \cline { 6 - 8 } & $\uparrow$ & $\leftrightarrow$ & $\downarrow$ & & $\uparrow$ & $\leftrightarrow$ & $\downarrow$ \\
$\mathcal{F}(i)$ & 34.7 & 45.1 & 20.2 & & 39.0 & 9.1 & 51.9 \\
$\mathcal{F}(\pi)$ & 71.0 & 0.3 & 28.7 & & 59.2 & - & 40.8 \\
$\mathcal{F}(u)$ & 23.2 & 55.2 & 21.6 & & 36.2 & 0.8 & 63.0 \\
& & & & & & & \\
$\mathcal{F}(i)^{0.2}$ & - & - & - & & - & - & - \\
$\mathcal{F}(\pi)^{0.2}$ & 67.0 & 8.6 & 24.5 & & 56.2 & 6.0 & 37.8 \\
$\mathcal{F}(u)^{0.2}$ & - & - & - & & 33.0 & 9.0 & 58.0 \\
& & & & & & & \\
$\mathcal{F}(i)^{0.5}$ & - & - & - & & - & - & - \\
$\mathcal{F}(\pi)^{0.5}$ & 60.2 & 21.1 & 18.7 & & 45.7 & 24.5 & 29.8 \\
$\mathcal{F}(u)^{0.5}$ & - & - & - & & 19.1 & 44.9 & 36.0 \\
\hline
\end{tabular}

It is also expected that consumer's forecasts will be influenced by both the current inflation and expert forecasts, usually through the media, as proposed by Carroll (2003). Figure 1 shows this can be true for inflation expectations, the only quantitative question of the Survey. In other words, the average inflation forecast of consumers and market experts $^{8}$ for the next 12 months shows a strong correlation with current inflation accumulated in 12 months up to the month observed, indicating that when forecasting future price changes households attribute a lot of weight to its current value, a kind of adaptive learning. ${ }^{9}$

Moreover, since consumer's forecasts always exceed the real data, they appear to observe an inflation rate that is higher than its current value. ${ }^{10}$ As we will construct the categorical variable based on realized inflation, this phenomenon can overestimate expectations of price increases. In Appendix A.2 we construct the

8 Median market expectations collected weekly by BCB's Focus survey, based on about 100 economists and financial market professionals and consulting firms.

9 To test this hypothesis, we performed a simple regression of the inflation expectation as a dependent variable and the inflation, interest rates, the unemployment rate, the expectations about the future variation of interest rate and unemployment as regressors. However, the null hypothesis of the joint test in which all coefficients are non-significant, with the exception of past inflation, was rejected suggesting that the hypothesis of strict adaptive expectations is not confirmed for Brazilian consumers, despite the high weight obtained for this coefficient.

10 The average and median forecast of the public for the entire period of analysis was $7.75 \%$ and $6 \%$, respectively, while the average annual variation of the IPCA was $5.25 \%$. 
Figure 1

Inflation's forecasts and IPCA in $t$

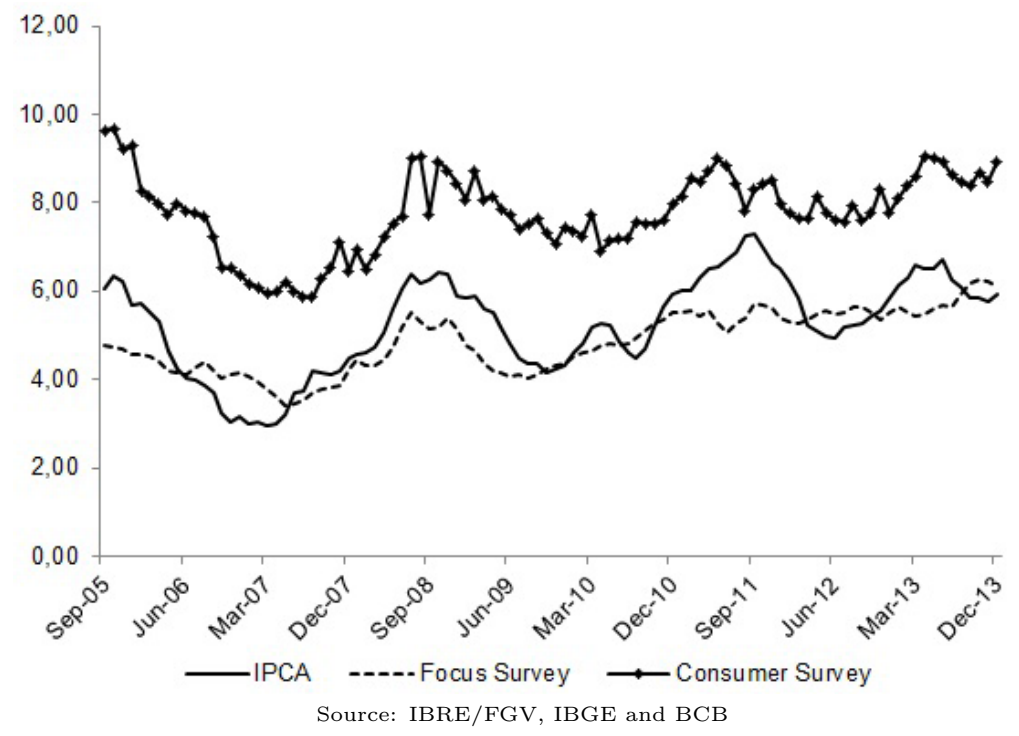

categorical variable based on the median inflation forecast of each individual and the median forecast of all individuals in each month of the analysis. The results of this exercise, in relation to what we will present in the next sections, show some similarities and support the previous conclusion.

The same pattern can be observed in the interest rate and unemployment forecasts, as shown in Figures 2 and 3. Because these questions are qualitative, we analyze the difference between proportions of the variables increasing and decreasing in a given 6-month period, which we call the "interest rate differential" and "labor differential", together with the Selic rate and the unemployment rate at the same time. Again, it seems that the individual relies on the present to predict the future, since the differential increases in moments of increases in the realized data.

The graphs also show that some movements in expectations seem to occur before the actual data. To verify this hypothesis, we performed Granger causality tests between expectations and realized data and the results presented in Appendix A.1 show that consumers are good predictors of the variables considered. 
Figure 2

Interest rate's forecasts and the Selic rate in $t$

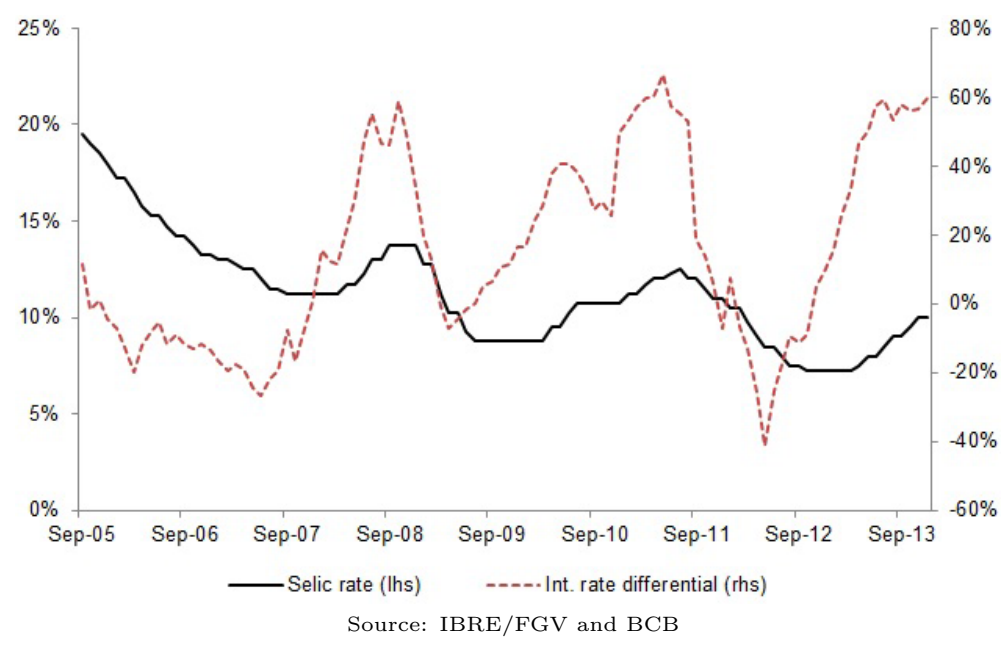

Figure 3

Employment's forecasts and the unemployment rate in $t$

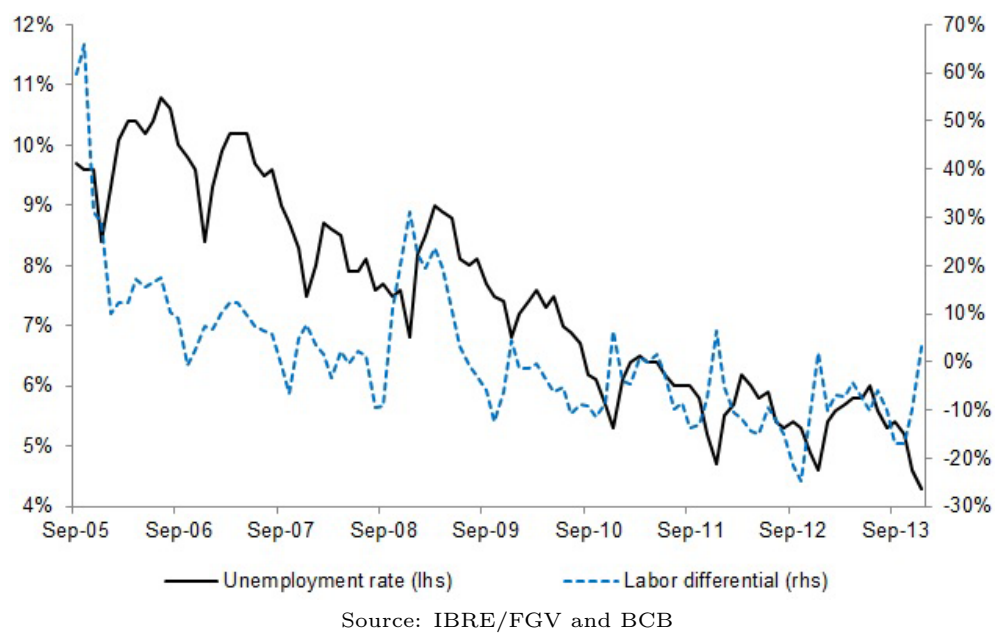

We are interested in evaluating the consistency of expectations through these predictions, and in the next section we detail how this treatment will be done. The period of analysis comprises the managements of Henrique Meirelles and Alexandre 
Tombini as heads of the Central Bank of Brazil. As we will show, it was a period marked by changes in the conduct of monetary policy, which may have influenced the formation of households' expectations about the variables involved.

We also analyze consistency according to sociodemographic characteristics of our sample. The survey divides individuals according to four levels of monthly income: up to $R \$ 2,100$, between $R \$ 2,100$ and $R \$ 4,800$, between $R \$ 4,800$ and $R \$ 9,600$ and above $\mathrm{R} \$ 9,600$. Five education levels: uneducated, full primary, middle school, high school, senior and postgraduate; besides sex and age divisions. However, as we will see in the next section, the results are homogeneous between levels.

\section{Consistency with the Taylor rule}

We will then proceed to the consistency analysis. In this section we evaluate whether Brazilian consumers form expectations consistent with the Taylor rule. As already mentioned, being consistent with the Taylor rule means understanding the causal relationship of changes in inflation and output on the interest rate. Thus, if an individual forecasts rising inflation and falling unemployment, to be consistent in a Taylor sense they should forecast increases in the interest rate, and vice versa.

It is important to consider that not being consistent with the Taylor rule does not mean misunderstanding the monetary policy adopted. The public's understanding of monetary policy is based both on the theoretical understanding of the rule framework and on the actions of the central bank given the surrounding environment. For this reason, in the next section we will also verify if there are changes in the formation of expectations according to the actions of the monetary authority.

Table 2 shows forecasts of the interest rate conditional on inflation and unemployment forecasts, according to the Consumer Survey. ${ }^{11}$ Each line brings the frequencies of such forecasts, i.e., $\mathcal{F}(i \mid \pi \uparrow, u \downarrow)$ indicates that among the consumers who predicted rising inflation and falling unemployment, $32 \%$ predicted an increase in interest rates, $45 \%$ a maintenance and $23 \%$ a drop. The data columns show the behavior of the central bank using the Selic rate in the months in which inflation and the unemployment rate followed the specified direction. ${ }^{12}$ As we see, regardless of

11 From now on we will only analyze the forecasts with a rounding of 0.2 p.p., but the general results remain for the other cases. 
the other variables' forecasts, the great majority of households forecast maintenance of the interest rate, as shown in Table 1, in most cases not obeying the Taylor rule. However, the realized data is more consistent with the rule, especially in cases of falling inflation. In the last two lines, for example, we see an indication that the $\mathrm{BCB}$ was consistent in all periods in which the rule recommended reducing interest rates, corresponding to 19 months of our sample.

Table 2

Conditional frequencies in the Survey and the data

\begin{tabular}{|c|c|c|c|c|c|c|c|c|}
\hline & \multicolumn{4}{|c|}{ Survey } & \multicolumn{4}{|c|}{ Data } \\
\hline & $\uparrow$ & $\leftrightarrow$ & $\downarrow$ & $\#$ & $\uparrow$ & $\leftrightarrow$ & $\downarrow$ & $\#$ \\
\hline $\mathcal{F}(i \mid \pi \uparrow, u \downarrow)$ & 32.0 & 44.9 & 23.1 & 21,085 & 53.6 & 7.1 & 39.3 & 28 \\
\hline $\mathcal{F}(i \mid \pi \uparrow, u \leftrightarrow)$ & 33.1 & 48.6 & 18.3 & 56,888 & 60.0 & 20.0 & 20.0 & 5 \\
\hline $\mathcal{F}(i \mid \pi \uparrow, u \uparrow)$ & 44.2 & 36.8 & 19.0 & 24,439 & 73.3 & - & 26.7 & 15 \\
\hline $\mathcal{F}(i \mid \pi \leftrightarrow, u \downarrow)$ & 29.3 & 42.5 & 28.2 & 3,215 & 50.0 & 16.7 & 33.3 & 6 \\
\hline $\mathcal{F}(i \mid \pi \leftrightarrow, u \leftrightarrow)$ & 29.5 & 46.5 & 24.0 & 7,383 & - & - & - & 0 \\
\hline $\mathcal{F}(i \mid \pi \leftrightarrow, u \uparrow)$ & 37.3 & 35.0 & 27.7 & 2,469 & 50.0 & - & 50.0 & 2 \\
\hline $\mathcal{F}(i \mid \pi \downarrow, u \downarrow)$ & 26.5 & 43.8 & 29.7 & 9,774 & 36.0 & - & 64.0 & 25 \\
\hline $\mathcal{F}(i \mid \pi \downarrow, u \leftrightarrow)$ & 31.2 & 47.5 & 21.3 & 20,570 & - & - & 100 & 2 \\
\hline $\mathcal{F}(i \mid \pi \downarrow, u \uparrow)$ & 37.7 & 35.5 & 26.8 & 6,941 & - & - & 100 & 17 \\
\hline
\end{tabular}

\subsection{OLS in expectations}

The frequencies in Table 2, while indicating a certain inconsistency of the public, do not allow us a very accurate conclusion. To verify empirically if household's expectations follow a Taylor rule we estimate the following Ordinary Least Squares (OLS) regression, with fixed effects at the individual level ${ }^{13}$ :

$$
E_{t}\left(\Delta i_{t, t+6}\right)=\alpha_{0}+\alpha_{1} E_{t}\left(\Delta \pi_{t, t+12}\right)+\alpha_{2} E_{t}\left(\Delta u_{t, t+6}\right)+\varepsilon
$$

where $E_{t}\left(\Delta i_{t, t+6}\right), E_{t}\left(\Delta \pi_{t, t+12}\right)$ and $E_{t}\left(\Delta u_{t, t+6}\right)$ pool all household's forecasts in time $t$ with the direction of the expected change in interest rate, inflation and unemployment, respectively, and $\varepsilon$ is the error term. The direction of expected changes of

12 In this case, the categorical variable of inflation was constructed for 6-months ahead to suit the variation of interest rate and unemployment.

13 Cluster-robust standard errors also at the individual level. 
inflation was calculated as the difference between the forecasted inflation 12-month ahead and the IPCA at the time of the answer, rounding off by 0.2 percentage points. We also estimate equation (1) incorporating only the numerical inflation forecast $E_{t}\left(\pi_{t+12}\right)$, as well as the difference between the 12-month inflation forecast and the median forecast of each household $E_{t}\left(\Delta \pi_{M, t+12}\right)$. The results are shown in Table 3.

Table 3

Taylor rule on expectations

\begin{tabular}{|c|c|c|c|c|c|}
\hline \multirow[b]{2}{*}{ Variables } & \multicolumn{5}{|c|}{ dependent variable: $E_{t}\left(\Delta i_{t, t+6}\right)$} \\
\hline & (1) & $(2)$ & (3) & $(4)$ & $(5)$ \\
\hline Constant & $\begin{array}{c}0.1220^{* * *} \\
(0.0014)\end{array}$ & $\begin{array}{c}0.0800^{* * *} \\
(0.0056)\end{array}$ & $\begin{array}{c}0.1282^{* * *} \\
(0.0000)\end{array}$ & $\begin{array}{c}0.1221^{* * *} \\
(0.0014)\end{array}$ & $\begin{array}{c}0.0796^{* * *} \\
(0.0056)\end{array}$ \\
\hline$E_{t}\left(\Delta u_{t, t+6}\right)$ & $\begin{array}{c}0.0437^{* * *} \\
(0.0040)\end{array}$ & $\begin{array}{c}0.0418^{* * *} \\
(0.0040)\end{array}$ & $\begin{array}{c}0.0318^{* * *} \\
(0.0039)\end{array}$ & & \\
\hline$E_{t}\left(\Delta \pi_{t, t+12}\right)$ & $\begin{array}{c}0.0144^{* * *} \\
(0.0034)\end{array}$ & & & $\begin{array}{c}0.0151^{* * *} \\
(0.0033)\end{array}$ & \\
\hline$E_{t}\left(\pi_{t+12}\right)$ & & $\begin{array}{c}0.0062^{* * *} \\
(0.0007)\end{array}$ & & & $\begin{array}{c}0.0063^{* * *} \\
(0.0007)\end{array}$ \\
\hline$E_{t}\left(\Delta \pi_{M, t+12}\right)$ & & & $\begin{array}{c}0.1341^{* * *} \\
(0.0032)\end{array}$ & & \\
\hline Observations & 152,743 & 152,743 & 152,743 & 152,743 & 152,743 \\
\hline$R^{2}$ & 0.002 & 0.002 & 0.030 & 0.000 & 0.004 \\
\hline Clusters & 14,298 & 14,298 & 14,298 & 14,298 & 14,298 \\
\hline
\end{tabular}

We can observe that inflation expectations have a positive and significant effect on interest rate forecasts, even when we consider the numerical forecast and the difference between realized inflation and the median individual forecast, a result that is consistent with the principles underlying the Taylor rule. On the other hand, the sign of the effect of unemployment expectations follows the same direction, not obeying the rule.

One possible explanation for this is that the BCB follows a strict inflation targeting regime, which can cause people to understand only the policy response to price 
changes. In addition, during the period considered we observed a certain dissociation of the unemployment rate from GDP growth in Brazil. In the years considered unemployment was characterized by successive falls and a not cyclical variation, immune to shocks that affected the Brazilian economy, which spoils this type of analysis. For these reasons, the last two columns show the estimation without the unemployment expectation as a regressor, and we see that the relationship between interest rates and inflation forecasts remains the same.

We also estimate (1) separated by levels of income and education. We analyze expectations of individuals with income below $\mathrm{R} \$ 2.100$ and above $\mathrm{R} \$ 9.600$, as well as individuals with education up to college and those who have at least a college degree. The results in Tables 4 and 5 show little heterogeneity in the consistency of expectations by demographics. Despite some differences in magnitude between the groups, both inflation and unemployment expectations have a positive and significant effect on interest rate forecasts. Thus, we cannot conclude that more educated or higher-income individuals better understand the Taylor rule than the others, and all groups present "inconsistency" in unemployment expectations in the rule framework (positive coefficient).

Table 4

Taylor rule on expectations by income

\begin{tabular}{|c|c|c|c|c|c|c|}
\hline Variables & \multicolumn{3}{|c|}{ Low income } & \multicolumn{3}{|c|}{ High income } \\
\hline Constant & $\begin{array}{c}0.1944^{* * *} \\
(0.0033)\end{array}$ & $\begin{array}{c}0.1778^{* * *} \\
(0.0067)\end{array}$ & $\begin{array}{c}0.2041^{* * *} \\
(0.0002)\end{array}$ & $\begin{array}{c}0.0538^{* * *} \\
(0.0024)\end{array}$ & $\begin{array}{l}-0.0109 \\
(0.0274)\end{array}$ & $\begin{array}{c}0.0629 * * * \\
(0.0000)\end{array}$ \\
\hline$E_{t}\left(\Delta u_{t, t+6}\right)$ & $\begin{array}{c}0.0603^{* * *} \\
(0.0078)\end{array}$ & $\begin{array}{c}0.0593^{* * *} \\
(0.0078)\end{array}$ & $\begin{array}{c}0.0517^{* * *} \\
(0.0077)\end{array}$ & $\begin{array}{c}0.0382^{* * *} \\
(0.0073)\end{array}$ & $\begin{array}{c}0.0362^{* * *} \\
(0.0073)\end{array}$ & $\begin{array}{c}0.0279 * * * \\
(0.0071)\end{array}$ \\
\hline$E_{t}\left(\Delta \pi_{t, t+12}\right)$ & $\begin{array}{c}0.0193^{* * *} \\
(0.0066)\end{array}$ & & & $\begin{array}{c}0.0263^{* * *} \\
(0.0064)\end{array}$ & & \\
\hline$E_{t}\left(\pi_{t+12}\right)$ & & $\begin{array}{c}0.0029 * * * \\
(0.0007)\end{array}$ & & & $\begin{array}{c}0.0108^{* * *} \\
(0.0040)\end{array}$ & \\
\hline$E_{t}\left(\Delta \pi_{M, t+12}\right)$ & & & $\begin{array}{c}0.0840^{* * *} \\
(0.0060)\end{array}$ & & & $\begin{array}{c}0.1648 * * * \\
(0.0060)\end{array}$ \\
\hline Observations & 30,169 & 30,169 & 30,169 & 43,493 & 43,493 & 43,493 \\
\hline $\mathrm{R}^{2}$ & 0.004 & 0.004 & 0.018 & 0.002 & 0.002 & 0.046 \\
\hline Clusters & 4,265 & 4,265 & 4,265 & 4,610 & 4,610 & 4,610 \\
\hline
\end{tabular}


Table 5

Taylor rule on expectations by education

\begin{tabular}{|c|c|c|c|c|c|c|}
\hline Variables & \multicolumn{3}{|c|}{ No college degree } & \multicolumn{3}{|c|}{ At least college degree } \\
\hline Constant & $\begin{array}{c}0.1742^{* * *} \\
(0.0024)\end{array}$ & $\begin{array}{c}0.1524^{* * *} \\
(0.0050)\end{array}$ & $\begin{array}{c}0.1786^{* * *} \\
(0.0001)\end{array}$ & $\begin{array}{c}0.0908^{* * *} \\
(0.0018)\end{array}$ & $\begin{array}{c}0.0164 \\
(0.0103)\end{array}$ & $\begin{array}{c}0.0971^{* * *} \\
(0.0001)\end{array}$ \\
\hline$E_{t}\left(\Delta u_{t, t+6}\right)$ & $\begin{array}{c}0.0465^{* * *} \\
(0.0061)\end{array}$ & $\begin{array}{c}0.0457^{* * *} \\
(0.0061)\end{array}$ & $\begin{array}{c}0.0383^{* * *} \\
(0.0060)\end{array}$ & $\begin{array}{c}0.0425^{* * *} \\
(0.0051)\end{array}$ & $\begin{array}{c}0.0392^{\text {*** }} \\
(0.0051)\end{array}$ & $\begin{array}{c}0.0284^{* * *} \\
(0.0050)\end{array}$ \\
\hline$E_{t}\left(\Delta \pi_{t, t+12}\right)$ & $\begin{array}{l}0.0096^{*} \\
(0.0051)\end{array}$ & & & $\begin{array}{c}0.0153^{* * *} \\
(0.0045)\end{array}$ & & \\
\hline$E_{t}\left(\pi_{t+12}\right)$ & & $\begin{array}{c}0.0031^{* * *} \\
(0.0006)\end{array}$ & & & $\begin{array}{c}0.0110^{* * *} \\
(0.0014)\end{array}$ & \\
\hline$E_{t}\left(\Delta \pi_{M, t+12}\right)$ & & & $\begin{array}{c}0.0994^{* * *} \\
(0.0047)\end{array}$ & & & $\begin{array}{c}0.1549^{* * *} \\
(0.0041)\end{array}$ \\
\hline Observations & 58,385 & 58,385 & 58,385 & 94,358 & 94,358 & 94,358 \\
\hline $\mathrm{R}^{2}$ & 0.002 & 0.002 & 0.021 & 0.002 & 0.002 & 0.042 \\
\hline Clusters & 6,765 & 6,765 & 6,765 & 10,012 & 10,012 & 10,012 \\
\hline
\end{tabular}

\subsection{Carvalho and Nechio (2014): Partial Effects}

Alternatively, we use the approach of Carvalho and Nechio (2014) to verify if the previous results maintain. The authors propose a particular method to test whether consumers understand the basic principles underlying the Taylor rule. Based on the conditional frequencies of consumer forecasts presented in Table 2, the partial effects of inflation and unemployment are defined below, and we set up a one-sided test where the null hypothesis is the inequality that violates the basic principles underlying the Taylor rule. Therefore, rejection of the null hypothesis leads to evidence that the partial effect tested follows the rule.

The advantage of this method is that considering only the specified conditional distribution allows asymmetries in responses in relation to cases not considered. In this way, we can better analyze whether partial effects obey the rule by focusing only on a specific case, each of the inequalities below.

Partial Effects of Inflation:

$$
\begin{aligned}
& H_{0}: \mathcal{F}(i \uparrow \mid \pi \downarrow, u \downarrow) \geq \mathcal{F}(i \uparrow \mid \pi \uparrow, u \downarrow) \\
& H_{0}: \mathcal{F}(i \uparrow \mid \pi \downarrow, u \uparrow) \geq \mathcal{F}(i \uparrow \mid \pi \uparrow, u \uparrow)
\end{aligned}
$$




$$
\begin{aligned}
& H_{0}: \mathcal{F}(i \downarrow \mid \pi \uparrow, u \downarrow) \geq \mathcal{F}(i \downarrow \mid \pi \downarrow, u \downarrow) \\
& H_{0}: \mathcal{F}(i \downarrow \mid \pi \uparrow, u \uparrow) \geq \mathcal{F}(i \downarrow \mid \pi \downarrow, u \uparrow)
\end{aligned}
$$

Partial Effects of Unemployment:

$$
\begin{aligned}
& H_{0}: \mathcal{F}(i \uparrow \mid \pi \downarrow, u \uparrow) \geq \mathcal{F}(i \uparrow \mid \pi \downarrow, u \downarrow) \\
& H_{0}: \mathcal{F}(i \uparrow \mid \pi \uparrow, u \uparrow) \geq \mathcal{F}(i \uparrow \mid \pi \uparrow, u \downarrow) \\
& H_{0}: \mathcal{F}(i \downarrow \mid \pi \downarrow, u \downarrow) \geq \mathcal{F}(i \downarrow \mid \pi \downarrow, u \uparrow) \\
& H_{0}: \mathcal{F}(i \downarrow \mid \pi \uparrow, u \downarrow) \geq \mathcal{F}(i \downarrow \mid \pi \uparrow, u \uparrow)
\end{aligned}
$$

In Table 6 we can see that the partial effects of inflation conform with the principles underlying the Taylor rule for the realized data in most cases, since we reject the null hypothesis in three of the four cases at a $5 \%$ significance level. ${ }^{14}$ The partial effects of unemployment violate Taylor's rule in two cases in which the null hypothesis is not rejected.

Table 6

Partial Effects on the data

\begin{tabular}{lcc}
\hline \multicolumn{3}{c}{ Partial Effects of Inflation } \\
\hline null hypothesis & mean diff. & p-value \\
$\mathcal{F}(i \uparrow \mid \pi \downarrow, u \downarrow) \geq \mathcal{F}(i \uparrow \mid \pi \uparrow, u \downarrow)$ & -0.1250 & 0.1717 \\
$\mathcal{F}(i \uparrow \mid \pi \downarrow, u \uparrow) \geq \mathcal{F}(i \uparrow \mid \pi \uparrow, u \uparrow)$ & -0.5912 & 0.0000 \\
$\mathcal{F}(i \downarrow \mid \pi \uparrow, u \downarrow) \geq \mathcal{F}(i \downarrow \mid \pi \downarrow, u \downarrow)$ & -0.2303 & 0.0397 \\
$\mathcal{F}(i \downarrow \mid \pi \uparrow, u \uparrow) \geq \mathcal{F}(i \downarrow \mid \pi \downarrow, u \uparrow)$ & -0.5912 & 0.0000 \\
\hline \multicolumn{3}{c}{ Partial Effects of Unemployment } \\
\hline null hypothesis & mean diff. & p-value \\
$\mathcal{F}(i \uparrow \mid \pi \downarrow, u \uparrow) \geq \mathcal{F}(i \uparrow \mid \pi \downarrow, u \downarrow)$ & -0.3161 & 0.0099 \\
$\mathcal{F}(i \uparrow \mid \pi \uparrow, u \uparrow) \geq \mathcal{F}(i \uparrow \mid \pi \uparrow, u \downarrow)$ & 0.1500 & 0.8585 \\
$\mathcal{F}(i \downarrow \mid \pi \downarrow, u \downarrow) \geq \mathcal{F}(i \downarrow \mid \pi \downarrow, u \uparrow)$ & -0.3162 & 0.0099 \\
$\mathcal{F}(i \downarrow \mid \pi \uparrow, u \downarrow) \geq \mathcal{F}(i \downarrow \mid \pi \uparrow, u \uparrow)$ & 0.0447 & 0.6280 \\
\hline
\end{tabular}

14

However, it should be taken into account that the symmetry of the distribution makes the second and fourth cases the same. 
Regarding the Consumer Survey, Table 7 shows that all partial effects of inflation follow the principles of the Taylor rule and are statistically significant at the usual levels. This means that the average public consistency, according to the specified inequality, is higher in cases that obey the rule. On the other hand, the partial effects of unemployment move in the opposite direction. In all cases we do not reject the null hypothesis, or do not follow the rule. The same conclusion can be made when we use the individual median for constructing the inflation forecast variable, as shown in Table 17 in Appendix A.2.

Table 7

Partial Effects on the Consumer Survey

\begin{tabular}{lcc}
\hline \multicolumn{3}{c}{ Partial Effects of Inflation } \\
\hline null hypothesis & mean diff. & p-value \\
$\mathcal{F}(i \uparrow \mid \pi \downarrow, u \downarrow) \geq \mathcal{F}(i \uparrow \mid \pi \uparrow, u \downarrow)$ & -0.1039 & 0.0000 \\
$\mathcal{F}(i \uparrow \mid \pi \downarrow, u \uparrow) \geq \mathcal{F}(i \uparrow \mid \pi \uparrow, u \uparrow)$ & -0.1031 & 0.0000 \\
$\mathcal{F}(i \downarrow \mid \pi \uparrow, u \downarrow) \geq \mathcal{F}(i \downarrow \mid \pi \downarrow, u \downarrow)$ & -0.1222 & 0.0000 \\
$\mathcal{F}(i \downarrow \mid \pi \uparrow, u \uparrow) \geq \mathcal{F}(i \downarrow \mid \pi \downarrow, u \uparrow)$ & -0.0846 & 0.0000 \\
\hline \multicolumn{3}{c}{ Partial Effects of Unemployment } \\
\hline null hypothesis & mean diff. & p-value \\
$\mathcal{F}(i \uparrow \mid \pi \downarrow, u \uparrow) \geq \mathcal{F}(i \uparrow \mid \pi \downarrow, u \downarrow)$ & 0.1405 & 1.0000 \\
$\mathcal{F}(i \uparrow \mid \pi \uparrow, u \uparrow) \geq \mathcal{F}(i \uparrow \mid \pi \uparrow, u \downarrow)$ & 0.1396 & 1.0000 \\
$\mathcal{F}(i \downarrow \mid \pi \downarrow, u \downarrow) \geq \mathcal{F}(i \downarrow \mid \pi \downarrow, u \uparrow)$ & 0.0923 & 1.0000 \\
$\mathcal{F}(i \downarrow \mid \pi \uparrow, u \downarrow) \geq \mathcal{F}(i \downarrow \mid \pi \uparrow, u \uparrow)$ & 0.0547 & 1.0000 \\
\hline
\end{tabular}

Our results were similar to those found by the authors for the American consumer. The Brazilian consumer seems to understand the relationship between inflation and interest rate within the framework of the Taylor rule, but does not seem to understand the relationship between unemployment and interest rate, a result that may have been influenced by the evolution of the unemployment rate series in the period and by the single mandate adopted by the $\mathrm{BCB}$, as mentioned previously.

We also consider the estimates by the cycle of the unemployment rate, as the authors do. We construct the unemployment gap as a measure of economic slack with the Hodrick-Prescott Filter in the unemployment rate, and we estimate the 
partial effects for the periods when the gap is positive and negative. In this case, unlike the American case, the perception of Brazilians in this approach does not change within the economic cycle.

Table 8

Partial Effects on the Consumer Survey

\begin{tabular}{|c|c|c|c|c|}
\hline \multicolumn{5}{|c|}{ Partial Effects of Inflation } \\
\hline & \multicolumn{2}{|c|}{ unemployment gap <0 } & \multicolumn{2}{|c|}{ unemployment gap $>0$} \\
\hline null hypothesis & mean diff. & p-value & mean diff. & p-value \\
\hline $\mathcal{F}(i \uparrow \mid \pi \downarrow, u \downarrow) \geq \mathcal{F}(i \uparrow \mid \pi \uparrow, u \downarrow)$ & -0.1441 & 0.0000 & -0.1623 & 0.0000 \\
\hline $\mathcal{F}(i \uparrow \mid \pi \downarrow, u \uparrow) \geq \mathcal{F}(i \uparrow \mid \pi \uparrow, u \uparrow)$ & -0.1264 & 0.0000 & -0.1302 & 0.0000 \\
\hline $\mathcal{F}(i \downarrow \mid \pi \uparrow, u \downarrow) \geq \mathcal{F}(i \downarrow \mid \pi \downarrow, u \downarrow)$ & -0.1441 & 0.0000 & -0.1623 & 0.0000 \\
\hline $\mathcal{F}(i \downarrow \mid \pi \uparrow, u \uparrow) \geq \mathcal{F}(i \downarrow \mid \pi \downarrow, u \uparrow)$ & -0.1264 & 0.0000 & -0.1302 & 0.0000 \\
\hline \multicolumn{5}{|c|}{ Partial Effects of Unemployment } \\
\hline & \multicolumn{2}{|c|}{ unemployment gap $<0$} & \multicolumn{2}{|c|}{ unemployment gap $>0$} \\
\hline null hypothesis & mean diff. & $\mathrm{p}$-value & mean diff. & $\mathrm{p}$-value \\
\hline $\mathcal{F}(i \uparrow \mid \pi \downarrow, u \uparrow) \geq \mathcal{F}(i \uparrow \mid \pi \downarrow, u \downarrow)$ & 0.1638 & 1.0000 & 0.1517 & 1.0000 \\
\hline $\mathcal{F}(i \uparrow \mid \pi \uparrow, u \uparrow) \geq \mathcal{F}(i \uparrow \mid \pi \uparrow, u \downarrow)$ & 0.1462 & 1.0000 & 0.1196 & 1.0000 \\
\hline $\mathcal{F}(i \downarrow \mid \pi \downarrow, u \downarrow) \geq \mathcal{F}(i \downarrow \mid \pi \downarrow, u \uparrow)$ & 0.1638 & 1.0000 & 0.1517 & 1.0000 \\
\hline $\mathcal{F}(i \downarrow \mid \pi \uparrow, u \downarrow) \geq \mathcal{F}(i \downarrow \mid \pi \uparrow, u \uparrow)$ & 0.1462 & 1.0000 & 0.1196 & 1.0000 \\
\hline
\end{tabular}

\subsection{Consistency Specifications}

However, one can say that if we change the directions of each variable in Table 2 it can misguide interpretations. In an economy with rising inflation and output, for example, a central bank that chooses to increase interest rates is not necessarily inconsistent, given its set of information and the outlook for the future of the economy. Theoretically, the optimal monetary policy would be characterized by a central bank that exerts such volatility in determining the interest rate as necessary to keep inflation and the level of employment in equilibrium.

For this reason, a well-defined measure of consistency underlying the Taylor rule is indispensable. Drager et al. (2013) characterize as consistent forecasts those that simultaneously point to: (i) rising interest rates, rising inflation and falling unemployment; (ii) rising interest rates accompanied by rising inflation or falling 
unemployment, with the other variable remaining constant; (iii) the same previous movements in opposite directions for cases of falling interest rates; or (iv) all variables constant. From the 27 possible cases, this specification considers only 7 cases of consistency, which may restrict the scope of analysis.

To better analyze these different possibilities, we define three specifications according to expected directions of each variable in the Taylor sense. The specifications are sums of each response frequency from the microdata. At the end, each measure will be an average proportion of all answers specified under total answers. The first measure follows Drager et al. (2013), described above, which we call Specification 1 , and the other two incorporate more cases to this one. Specification 2 considers cases in which interest rates follow opposite directions to unemployment as proposed by the rule, and Specification 3 adds cases of "inconsistency" for inflation or unemployment, separately, at times of constant interest rates: ${ }^{15}$

$$
\begin{array}{r}
\text { Specification 1: } F(i \uparrow, \pi \uparrow, u \downarrow)+F(i \uparrow, \pi \uparrow, u \leftrightarrow)+F(i \uparrow, \pi \leftrightarrow, u \downarrow)+ \\
F(i \downarrow, \pi \downarrow, u \uparrow)+F(i \downarrow, \pi \leftrightarrow, u \uparrow)+F(i \downarrow, \pi \downarrow, u \leftrightarrow)+F(i \leftrightarrow, \pi \leftrightarrow, u \leftrightarrow) \\
\text { Specification 2: Specification } 1+F(i \uparrow, \pi \uparrow, u \uparrow)+F(i \downarrow, \pi \downarrow, u \downarrow)
\end{array}
$$$$
\text { Specification 3: Specification } 2+F(i \leftrightarrow, \pi \leftrightarrow, u \uparrow)+F(i \leftrightarrow, \pi \leftrightarrow, u \downarrow)+
$$
$F(i \leftrightarrow, \pi \uparrow, u \leftrightarrow)+F(i \leftrightarrow, \pi \downarrow, u \leftrightarrow)$

Figure 4 shows that the three specifications present similar patterns in the analyzed period, and the more cases we incorporate the higher the consistency level. Specification 3 oscillates around an average of $60 \%$ of total responses in the considered period, indicating a reasonable number of consistent responses according to our measure. ${ }^{16}$ Despite fluctuations in general, it is worth noting the strong decline in the average public consistency in 2012 in all specifications, which will be explored in the next section.

15 We only want to relax the definition of consistency, since it is not trivial to define an unquestionable specification. Inconsistency of a variable separately means that its relation to the interest rate does not follow the basic principles underlying the Taylor rule, while the other variable follows the rule. The third specification, the least restrictive, considers 13 cases of consistency among the 27 possible ones, the other 14 cases being defined as inconsistent in the sense of Taylor. As the $\mathrm{BCB}$ follows a strict inflation targeting regime, we define that a negative correlation between interest rates and inflation is a clearer sign of inconsistency than it is for unemployment.

16 From now on, only this specification will be used for the analyzes and estimates. The tests performed for specifications 1 and 2 indicate similar results and are presented in the Appendix A.3. 
Figure 4

Consistency proportions by specification

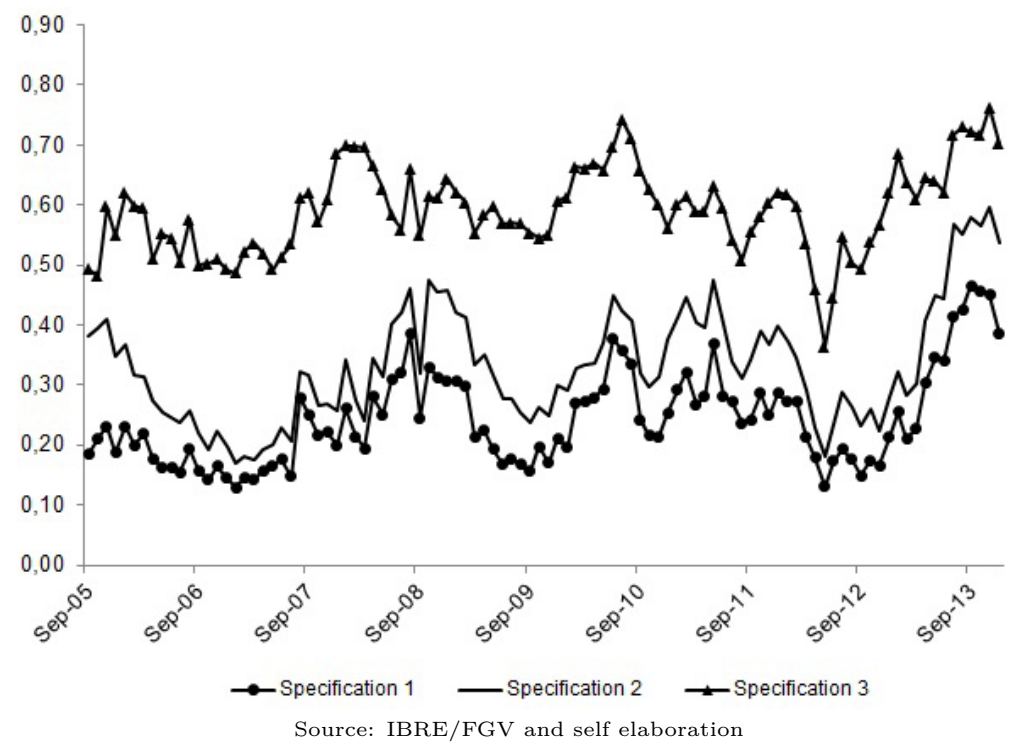

\section{Consistency and the Central Bank}

The understanding of monetary policy is not only based in theory, it also represents the actions of the central bank given the local economic environment. In this section, we analyze the evolution of consumer's consistency according to the monetary policy adopted by the Central Bank of Brazil in the analyzed period. With this, we can identify if consumers follow the conduct of monetary policy in Brazil. Initially, we use the same consistency specifications used for the consumer, this time for the monetary authority, and we take an alternative approach using the reaction function.

The application of the same measures specified above for the central bank, however, has a different interpretation since we are looking for realized data instead of expectations. Initially, we observe the variables' directions in the 6-month period. In this case, by comparing the consumers and BCB's consistency, we are assuming that the public may be anticipating the central bank's actions, thereby incorporating a possible deviation from the Taylor rule in their forecasts, a hypothesis closer to rational expectations. On the other hand, if we analyze the direction of the variables 
in relation to its past, we assume that households only consider past decisions of monetary policy when forecasting, more related to adaptive expectations. The two forms are considered, i.e., the variations from $t$ to $t+6$ or to $t-6$.

In the first case, the measure says that the BCB deviated from the Taylor rule in three periods: December 2006 to September 2007, March to September 2012 and January to August 2013. In the second case, when observing past actions of the BCB, we identify deviation from the rule in the periods: May 2007 to March 2008, September 2012 to March 2013 and August to December 2013. Obviously, we are dealing with the same measure only deferred some periods in time, but we are trying to look for different angles by which the public observes monetary policy to form their expectations.

A simple method to understand if the Brazilian consumer perceives monetary policy movements over time is to verify if there are changes of expectations in the periods in which the central bank changes its behavior. To quantify this effect, we propose a statistical test that compares the average consumer consistency in periods the BCB deviated from the rule in comparison with the other periods. Let $B C$ be a binary variable that assumes the value 1 if in the month considered the central bank obey the Taylor rule and 0 otherwise, and $C_{B C}$ the average proportion of consistent expectations in the period, we wish to test the hypothesis: $C_{B C=0}-C_{B C=1} \geq 0$

Table 9 shows the results with the variations regarding the future of the variables. We see a significant difference in the public's consistency in these months, since the null hypothesis that consistency did not change between these periods is rejected up to $1 \%$. This result amounts to evidence that the public changes their perceptions about monetary policy before the BCB deviates from the Taylor rule. Thus, consumers would be anticipating changes in the monetary authority's behavior and incorporating this to future forecasts.

Nevertheless, when we analyze the past horizon, the average public's consistency in the supposed months of deviation is even higher than in other months, so the test does not reject the null hypothesis in the one-sided test. That is, if the public considers only the past when forming expectations about the future of monetary policy, a deviation from the Taylor rule before the forecast does not reduce consumer's consistency. One possible explanation for this result is that shortly 
Table 9

Difference in people's consistency

\begin{tabular}{|c|c|c|c|}
\hline Test & $\# \mathrm{Obs}_{B C=0}$ & mean diff. & $\mathrm{p}$-value \\
\hline Future horizon & & & \\
\hline$H_{0}: C_{B C=0} \geq C_{B C=1}$ & 25 & -0.0451 & 0.0033 \\
\hline Past horizon & & & \\
\hline$H_{0}: C_{B C=0} \geq C_{B C=1}$ & 23 & 0.0631 & 0.9999 \\
\hline
\end{tabular}

after the deviations households will expect a correction of the monetary authority's behavior in the following months, like a compensation for the deviation.

\subsection{Central Bank Reaction Function deviations}

The disadvantage of analyzing the behavior of the central bank through these measures is that we are not taking into account the level of the variables, and then their variation around the equilibrium, an important analysis for central banks. In addition, as well as the partial effects of Carvalho and Nechio (2014), this method does not allow us to impose a distribution structure on the data in order to make an inference.

To not just focus only on a previously defined measure and to use a more common method in the literature to evaluate the actions of the monetary authority, we will estimate a Central Bank Reaction Function as follows:

$$
i_{t}=\alpha_{1} i_{t-1}+\left(1-\alpha_{1}\right)\left(\alpha_{2}+\alpha_{3}\left(E_{t} \pi_{t+12}-\pi_{t}^{*}\right)+\alpha_{4} y_{t-2}\right)+\varepsilon
$$

where $i$ is the Selic target determined by the monetary authority, $E_{t} \pi_{t+12}$ is the expected inflation for the next 12 months, $\pi^{*}$ is the inflation target, $y_{t-2}$ is the output gap and $\varepsilon$ the error term.

As we are using monthly data in the estimation, the interest rate variable will have a strong inertia between lags by construction since it is the policy rate determined at the meetings of the Monetary Policy Committee (COPOM), which happen every 45 days. The presence of the dependent variable lagged one period 
among the regressors represents the hypothesis that the central bank wishes to make smooth changes in the short-term rate, so that the parameter $\alpha_{1}$ will oscillate within the interval $(0,1)$.

The variable of expectations minus the inflation target is constructed using forecasts for inflation 12-months ahead from the Focus Survey. Later in this paper, we estimate for years prior to 2005 when the inflation target changes. Thus, we will modify the calculation of this variable according to the method used in Minella et al. $(2003)^{17}$, which weighs the deviations according to the month in which the forecast is made.

In calculating the output gap, we will use the industrial production beacuse it's a monthly series and calculate the gap through the Hodrick-Prescott Filter. This series is delayed two months due to release dates.

We also estimate equation (2) in rolling windows of 40 observations (months), so that in each window we repeat the last 20 observations in order to identify behavior changes of the monetary authority in sub-periods of our sample. Thus, the sub-periods are: 1st window: September 2005 to December 2008; 2nd window: May 2007 to August 2010; 3rd window: January 2009 to April 2012 and 4th window.: September 2010 to December 2013.

The Table 10 shows the results of the estimation of a simple Taylor rule for the BCB from September 2005 to December 2013 and each window in the order above. As we can see, the inflation variable is not significant over the whole period, while the lagged Selic rate's coefficient shows strong interest rate inertia, due to the higher autocorrelation structure in the series. The output gap also has a significant and expected signal in the estimation.

Analyzing the results, we see that the BCB changed the orientation of monetary policy between the sub-periods. The insignificance of the output gap coefficient

17 According to the authors, the inflation expectations variable should be constructed as follows:

$$
D_{j}=\frac{(12-j)}{12}\left(E_{j} \pi_{t}-\pi_{t}^{*}\right)+\frac{j}{12}\left(E_{j} \pi_{t+1}-\pi_{t+1}^{*}\right)
$$

where $D_{t}$ is the measure of expectation deviation from the target, $j$ is the month index and $t$ the year index. 
Table 10

Rolling Central Bank Reaction Function

\begin{tabular}{|c|c|c|c|c|c|}
\hline Variables & (1) & $(1$ st W) & $(2 \mathrm{nd} \mathrm{W})$ & $(3 r d ~ W)$ & $(4$ th W) \\
\hline Constant & $\begin{array}{c}0.4773^{* * *} \\
(0.1473)\end{array}$ & $\begin{array}{c}1.4222^{* * *} \\
(0.3590)\end{array}$ & $\begin{array}{c}1.1230 * * * \\
(0.3947)\end{array}$ & $\begin{array}{c}0,8857 \\
(0.5718)\end{array}$ & $\begin{array}{c}0.5510 \\
(0.3469)\end{array}$ \\
\hline Selic $_{t-1}$ & $\begin{array}{c}0.9491^{* * *} \\
(0.0119)\end{array}$ & $\begin{array}{c}0.8922^{* * *} \\
(0.0233)\end{array}$ & $\begin{array}{c}0.8954^{* * *} \\
(0.0353)\end{array}$ & $\begin{array}{c}0.9172^{* * *} \\
(0.0595)\end{array}$ & $\begin{array}{c}0.9266^{* * *} \\
(0.0262)\end{array}$ \\
\hline$E_{t} \pi_{t+12}-\pi^{*}$ & $\begin{array}{c}0.0137 \\
(0.0517)\end{array}$ & $\begin{array}{c}0.4101^{* * * *} \\
(0.1113)\end{array}$ & $\begin{array}{c}0.2514^{* *} \\
(0.1170)\end{array}$ & $\begin{array}{l}-0.1177 \\
(0.1967)\end{array}$ & $\begin{array}{c}0.0726 \\
(0.1577)\end{array}$ \\
\hline$y_{t-2}$ & $\begin{array}{c}0.0609^{* * *} \\
(0.008859)\end{array}$ & $\begin{array}{l}-0.0086 \\
(0.0236)\end{array}$ & $\begin{array}{c}0.0490^{* * *} \\
(0.0112)\end{array}$ & $\begin{array}{c}0.0666^{* * *} \\
(0.0181)\end{array}$ & $\begin{array}{c}0.1308^{* * *} \\
(0.0214)\end{array}$ \\
\hline Observations & 100 & 40 & 40 & 40 & 40 \\
\hline Adjusted- $R^{2}$ & 0.9871 & 0.9894 & 0.9541 & 0.9176 & 0.9797 \\
\hline
\end{tabular}

from September 2005 to December 2008 indicates that the monetary authority does not appear to have acted according to the principles of the Taylor rule in relation to activity in the period. Then, the results for the third and fourth windows show that from 2009 there was a significant greater tolerance to inflationary deviations from the target, which includes the end of Henrique Meirelles' term and a large part of Alexandre Tombini's term.

At the same time, the dispersion of consumer inflation expectations increases in this second period, as shown in Figure 5. Since the end of 2010, the households interviewed seem more confused about their inflation forecast than in previous years, considering the expectation relative to both the IPCA and the median individual forecast.

Based on these periods, we applied the same mean difference test to verify if there was a change in the public expectations between the windows. Table 11 shows the results. While in the first window there seems to be a change in the mean consistency at the $5 \%$ level of significance, in the others we do not reject the null 
Figure 5

Standard deviation of inflation expectations

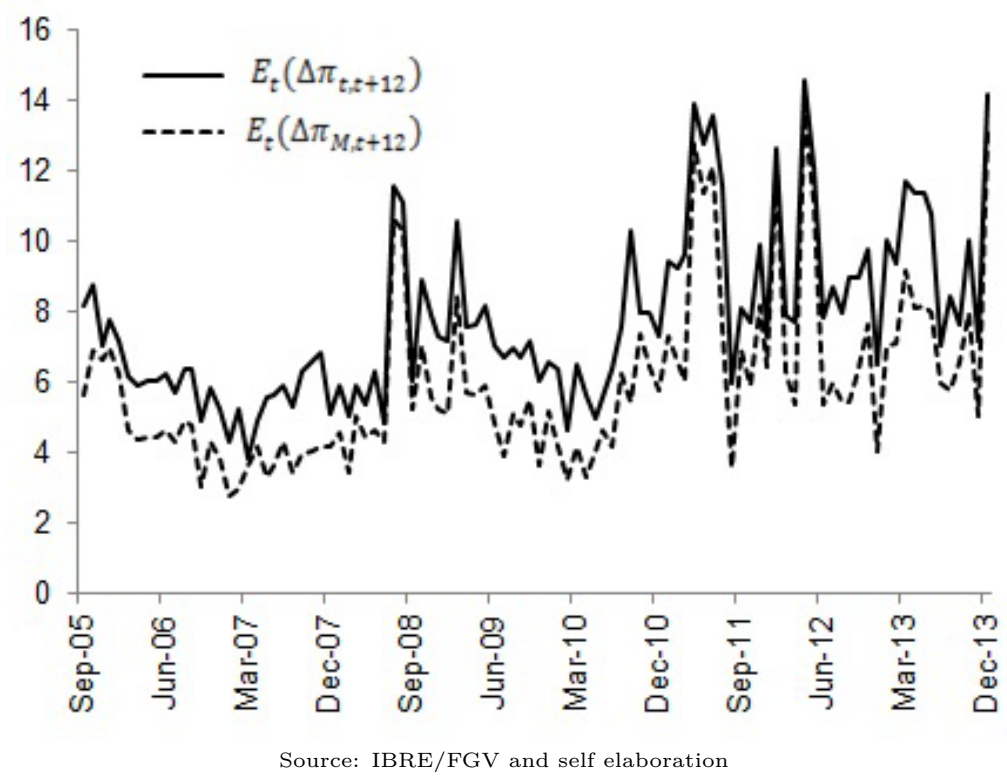

hypothesis, a result that is not expected due to the strong decrease in consistency observed in 2012.

That is, when we analyze the behavior of the BCB in moving windows, the tests amounts to evidence that there seems to be changes in the households' expectation formation only in the first window. This result indicates that changes in the monetary policy reaction to the output gap may have influenced public expectations, but the same does not occur for the period in which there seems to be a change in the response to inflation.

On the other hand, the results in Appendix A.2 show that there was a change in consumer perception in the third and fourth window when we use the median forecast instead of the IPCA to construct the categorical variable of inflation expectations.

Similarly, the estimation of the equation (1) separated in these windows, shown in Table 12 below, shows that the coefficient of inflation expectation is no 
Table 11

Difference in people's consistency

\begin{tabular}{|c|c|c|c|}
\hline Test & $\# \mathrm{Obs}_{B C=0}$ & mean diff. & p-value \\
\hline \multicolumn{4}{|l|}{ 1st window } \\
\hline$H_{0}: C_{B C=0} \geq C_{B C=1}$ & 40 & -0.0313 & 0.0170 \\
\hline \multicolumn{4}{|l|}{ 2nd window } \\
\hline$H_{0}: C_{B C=0} \geq C_{B C=1}$ & 40 & 0.0372 & 0.9942 \\
\hline \multicolumn{4}{|l|}{ 3rd window } \\
\hline$H_{0}: C_{B C=0} \geq C_{B C=1}$ & 40 & 0.0139 & 0.8238 \\
\hline \multicolumn{4}{|l|}{ 4th window } \\
\hline$H_{0}: C_{B C=0} \geq C_{B C=1}$ & 40 & 0.0108 & 0.7644 \\
\hline
\end{tabular}

longer significant in the fourth window, also indicating a more apparent change in consumer expectations in this period.

Still, despite the significant result the data shows us that the deviation periods seem to have been much more specific than the whole 40-month windows. According to Balbino, Colla and Teles (2011), the BCB maintained the same behavior in conducting monetary policy between 1999 and 2009. Thus, the deviation from the Taylor rule observed in Table 10 seems to be more concentrated in mid-2011, when the $\mathrm{BCB}$ reversed a cycle of rate increases and initiated a cycle of rate cuts even with inflation rising and close to the target upper bound.

If we estimate the reaction function since 2002 , a period that includes a good part of the targeting regime initiated in Arminio Fraga's term, it is evident the change of conduct in Tombini's term. In Table 13, column (1) shows the estimation results from January 2002 to December 2013, column (2) from January 2002 to July 2011 and column (3) from August 2011, the starting month of the rate cuts cycle, to December 2013. The results show that until 2011 BCB followed a simple Taylor rule in the conduct of monetary policy, but since this year there was a deviation from the rule in the relation to interest rates and inflation, as expected, and greater weight given to the output gap. Despite little recent empirical evidence, the analysts' 
Table 12

Rolling Taylor rule on expectations

\begin{tabular}{|c|c|c|c|c|}
\hline Variables & $(1 \mathrm{st} W)$ & $(2 \mathrm{nd} \mathbf{W})$ & $(3 r d W)$ & $(4$ th W) \\
\hline Constant & $\begin{array}{c}-0.0090^{* * *} \\
(0.0029)\end{array}$ & $\begin{array}{c}0.1137^{* * *} \\
(0.0023)\end{array}$ & $\begin{array}{c}0.1974^{* * *} \\
(0.0016)\end{array}$ & $\begin{array}{c}0.2640^{* * *} \\
(0.0014)\end{array}$ \\
\hline$E_{t}\left(\Delta u_{t, t+6}\right)$ & $\begin{array}{c}0.0474^{* * *} \\
(0.0054)\end{array}$ & $\begin{array}{c}0.0320^{* * *} \\
(0.0067)\end{array}$ & $\begin{array}{c}0.0349^{* * *} \\
(0.0064)\end{array}$ & $\begin{array}{c}0.0603^{* * *} \\
(0.0054)\end{array}$ \\
\hline$E_{t}\left(\Delta \pi_{t, t+12}\right)$ & $\begin{array}{l}0.0104^{*} \\
(0.0053)\end{array}$ & $\begin{array}{c}0.0297^{* * *} \\
(0.0051)\end{array}$ & $\begin{array}{c}0.0229 * * * \\
(0.0049)\end{array}$ & $\begin{array}{c}0.0026 \\
(0.0046)\end{array}$ \\
\hline Observations & 61,486 & 59,184 & 62,245 & 61,506 \\
\hline$R^{2}$ & 0.002 & 0.002 & 0.002 & 0.003 \\
\hline Clusters & 6,635 & 6,097 & 8,903 & 8,402 \\
\hline
\end{tabular}

consensus is that the BCB has been overly lenient with inflation since the end of 2011 until $2014 .^{18}$

Figure 6 shows forecasts for Selic from August 2011, based on the estimation of (2) starting from 2002 or 2005. If the BCB had maintained the same behavior in conducting the monetary policy adopted in previous years, the determination of the policy rate should have been narrowly more restrictive to inflationary deviations, which shows that the Tombini's term deviated from the average rule until then.

Nevertheless, this was the period that the average public consistency reached its lowest level. Table 14 presents the results for the average consistency's difference test in the periods: August 2011 to October 2012, which marks the beginning of the Selic rate cuts cycle to stabilization and August 2011 to March 2013, which marks the beginning of the rate cuts to first month of an increase in rates. In both cases we see that there is a significant difference in the average consistency of the public in these periods, especially in the first case, where we have the most significant deviation from the Taylor rule.

18 See for example Gustavo Loyola for Valor Econômico newspaper on July 2015: http://www. valor.com.br/opiniao/4122024/credibilidade-do-bc-custa-caro 
Table 13

BCB deviation in 2011

\begin{tabular}{lccc}
\hline Variables & $(\mathbf{1})$ & $\mathbf{( 2 )}$ & $\mathbf{( 3 )}$ \\
\hline Constant & -0.0066 & 0.3162 & 0.4359 \\
& $(0.1410)$ & $(0.1966)$ & $(0.3458)$ \\
& & & \\
Selic $t-1$ & $0.9894^{* * *}$ & $0.9700^{* * *}$ & $0.9016^{* * *}$ \\
& $(0.0096)$ & $(0.0129)$ & $(0.0268)$ \\
$E_{t} \pi_{t+12}-\pi^{*}$ & $0.2072^{* * *}$ & $0.3065^{* * *}$ & 0.3417 \\
& $(0.0545)$ & $(0.0690)$ & $(0.2062)$ \\
& & & \\
$y_{t-2}$ & $0.0720^{* * *}$ & $0,0617^{* * *}$ & $0.1023^{* * *}$ \\
& $(0.0143)$ & $(0.0159)$ & $(0.0274)$ \\
& & & 29 \\
Observations & 142 & 113 & 0.9766 \\
\hline Adjusted- $R^{2}$ & 0.9870 & 0.9841 &
\end{tabular}

In addition, the estimation of equation (1) separated for these two periods of deviation also points to changes in expectations. In Table 15 we can see that the public's expectations show a signal reversal for inflation responses to interest rates in periods when the $\mathrm{BCB}$ is more lenient to inflation, while the unemployment effect remains with the same sign. The result is practically the same for the two deviation periods considered. In this way, consumers appear to change their perception about monetary policy in these periods and become less consistent with the Taylor rule.

As the central bank adopted a more dovish behavior until early 2013, we believe that it was the main driver for the decline in public consistency observed during this period, with a greater magnitude in 2012. Not only because of the change in monetary policy stance compared to the past, but also by disobedience to the theoretical rule of monetary policy, the BCB caused a misalignment in household's expectations during the period, which may have damaged the transmission channel and the efficiency of monetary policy. 
Figure 6

BCB deviations from 2011

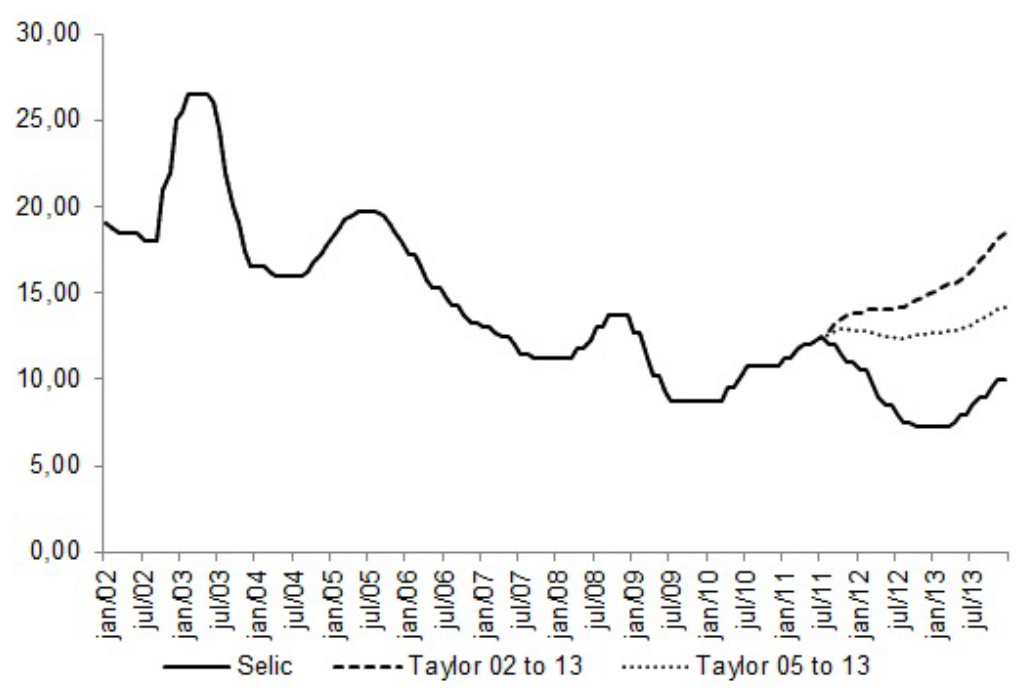

Source: BCB and self elaboration

Table 14

Difference in people's consistency

\begin{tabular}{|c|c|c|c|}
\hline Test & $\# \mathrm{Obs}_{B C}=0$ & mean diff. & $\mathrm{p}$-value \\
\hline \multicolumn{4}{|c|}{ Aug. 2011 to Oct. 2012: } \\
\hline$H_{0}: C_{B C=0} \geq C_{B C=1}$ & 15 & -0.0716 & 0.0002 \\
\hline \multicolumn{4}{|c|}{ Aug. 2011 to Mar. 2013: } \\
\hline$H_{0}: C_{B C=0} \geq C_{B C=1}$ & 20 & -0.0472 & 0.0044 \\
\hline
\end{tabular}


Table 15

Taylor rule on expectations

dependent variable: $E_{t}\left(\Delta i_{t, t+6}\right)$

\begin{tabular}{|c|c|c|c|c|}
\hline \multirow[b]{2}{*}{ Variables } & \multicolumn{2}{|c|}{ Aug. 2011 to Oct. 2012} & \multicolumn{2}{|c|}{ Aug. 2011 to Mar. 2013} \\
\hline & Desviation & Others & Desviation & Others \\
\hline Constant & $\begin{array}{c}-0.0727^{* * *} \\
(0.0021)\end{array}$ & $\begin{array}{c}0.1553^{* * *} \\
(0.0016)\end{array}$ & $\begin{array}{c}-0.0143^{* * *} \\
(0.0017)\end{array}$ & $\begin{array}{c}0.1565^{* * *} \\
(0.0017)\end{array}$ \\
\hline$E_{t}\left(\Delta u_{t, t+6}\right)$ & $\begin{array}{c}0.0430 * * * \\
(0.0081)\end{array}$ & $\begin{array}{c}0.0341^{* * *} \\
(0.0043)\end{array}$ & $\begin{array}{c}0.0441^{* * *} \\
(0.0069)\end{array}$ & $\begin{array}{c}0.0348^{* * * *} \\
(0.0045)\end{array}$ \\
\hline$E_{t}\left(\Delta \pi_{t, t+12}\right)$ & $\begin{array}{c}-0.0596^{* * *} \\
(0.0065)\end{array}$ & $\begin{array}{c}0.0276^{* * *} \\
(0.0037)\end{array}$ & $\begin{array}{c}-0.0597^{* * *} \\
(0.0057)\end{array}$ & $\begin{array}{c}0.0241^{* * *} \\
(0.0038)\end{array}$ \\
\hline Observations & 23,328 & 129,436 & 30,201 & 122,563 \\
\hline$R^{2}$ & 0.007 & 0.002 & 0.007 & 0.002 \\
\hline Clusters & 3,864 & 13,382 & 4,244 & 13,148 \\
\hline
\end{tabular}




\subsection{Endogeneity}

Possible problems of endogeneity may also arise when using the methods discussed so far. In cases where monetary shocks influence the endogenous determination of inflation and unemployment, the estimates can become biased and modify the correct causal interpretation among the variables.

Besides these shocks did not have great effects on the American case, Carvalho and Nechio (2014) argue that the bias caused did not modify the signs of the parameters considered, only the magnitude, not altering the main conclusions.

For the Brazilian case, we estimate a structural VAR (SVAR) and decompose the monetary policy shocks to verify this effect. We find that these shocks are not relevant to explain the inflation and unemployment rate dynamics in Brazil in the analyzed period. In general, monetary shocks explain approximately $2 \%$ to $4 \%$ of the inflation variance and between $2 \%$ to $3 \%$ of the variation in unemployment or the output gap in up to 12 months. When we consider market's inflation expectations as in equation (2), the monetary policy shocks explain about $10 \%$ of the variance of this variable. In this way, we can also conclude that these shocks do not alter the main conclusions of the paper.

\section{Conclusion}

In this paper, we investigate whether Brazilian consumers understand the conduct of the monetary policy by the Central Bank of Brazil when analyzing the evolution of the consistency of expectations about the Taylor rule. Despite the recent progress in the literature on monetary policy in general, there is little evidence of public expectations about macroeconomic aggregates, despite the importance of households in determining prices in the economy and its political importance for the autonomy of the central bank.

From the work of Carvalho and Nechio (2014), we redirected the focus to the behavior of expectations in Brazil from deviations of the central bank in the period from 2005 to 2013. Initially, as in the US case, we found evidence that the Brazilian consumer correctly understands the relationship between interest rates and inflation underlying the Taylor rule's framework, but it is not the case for the unemployment 
rate probably because of specific characteristics of this series in recent years and the monetary policy regime adopted in Brazil. Therefore, this different perception does not necessarily mean misunderstanding about the principles of the rule.

Since we are evaluating expectations in relation to a theoretical rule of policy, deviations in the behavior of the monetary authority can be expected to have a direct impact on individuals' expectations. Our results also show that there was a significant change in the average consistency of expectations in the periods when the BCB deviated from the rule, or assumed a more tolerant posture to inflationary shocks. Probable consequences for these events range from the loss of credibility to the deterioration of the monetary policy transmission mechanism.

\section{References}

Balbino, C. E., Colla, E., Teles, V. K. (2011). A Política Monetária Brasileira sob o Regime de Metas de Inflação. Revista Brasileira de Economia, vol. 65(2): 113-126.

Blinder, A. S., Ehrman, M., Fratzscher, M., De Haan, J. and Jansen, D-J. (2008). Central Bank Communication and Monetary Policy: A Survey of Theory and Evidence. ECB Working Paper Series n. 898.

Carroll, C. (2003). Macroeconomic Expectations of Households and Professional Forecasters. The Quarterly Journal of Economics, MIT Press, vol. 118(1): 269-298.

Carvalho, F. and Minella, A. (2012). Survey forecasts in Brazil: A prismatic assessment of epidemology, performance, and determinants. Journal of International Money and Finance, 31: 1371-1391.

Carvalho, C. and Nechio, F. (2014). Do People Understand Monetary Policy? Journal of Monetary Economics vol. 66, 108-123.

Coibion, O. and Y. Gorodnichenko (2012). What Can Survey Forecasts Tell Us About Information Rigidities?. Journal of Political Economy, 120(1): 116-159. 
Drager, L., Lamla, M. J. and Pfajfar, D. (2013). Are Consumers Expectations Theory-Consistent? The Role of Macroeconomic Determinants and Central Bank Communication. KOF Working Papers n. 345.

Mankiw, N. G., Reis, R. and Wolfers, J. (2004). Disagreement about inflation expectations. NBER Macroeconomics Annual 2003, vol. 18, 209-248.

Mitchell, K. and Pearce, D. (2009). Do Wall Street economists believe in Okun's Law and the Taylor Rule?. Journal of Economics and Finance, 34: 196-217.

Minella, A., Freitas, P.S., Goldfajn, I. and Muinhos, M.K. (2003), Inflation Targeting in Brazil: Constructing Credibility under Exchange Rate Volatility. $B C B$ Working Paper Series n.77.

Moreira, T. B. S., Souza, G. S. and Ellery Jr, R. (2013). An Evaluation of the Tolerant to Higher Inflation Rate in the Short Run by the Brazilian Central Bank in the Period 2001-2012. Revista Brasileira de Economia, vol. 67(4): 485-500.

Preston, B. (2006). Adaptative Learning, forecast-based instrument rules and monetary policy. Journal of Monetary Economics, 53: 507-535.

Souleles, N. S. (2004). Expectations, heterogeneous forecast erros, and consumption: Micro evidence from the Michigan consumer sentiment surveys. Journal of Money, Credit and Banking, 36(1): 40-72.

Svensson, L. E. O. (2003). What Is Wrong with Taylor Rules? Using Judgment in Monetary Policy through Targeting Rules. Journal of Economic Literature, 41(2): 427-477.

Taylor, J. (1993), Discretion versus policy rules in practice. Carnegie-Rochester Conference Series on Public Policy 39: 195-214.

Tombini, A. (2011). Inauguration speech as president of the Central Bank of Brazil.

Yellen, J. L. (2015). Semiannual Monetary Policy Report to the Congress. Before the Committee on Financial Services, U.S. House of Representatives, Washington, D.C. 


\section{A. Appendix}

\section{A.1 Forecasts and realized data}

Figures 1 to 3 suggest that expectations seem to anticipate the realized data. We can empirically verify whether consumers anticipate these movements at certain periods by a Granger causality test between the expectations and the actual data at the time of the question. If past values of expectations help to explain the contemporary values of the variable, we can consider the consumer a good predictor of this variable. The p-values described in Table 16 show that when we consider one or six lags, we reject the null hypothesis that forecasts do not Granger cause inflation, interest rate, and unemployment, suggesting that consumers can anticipate to some extent the movements of the data.

Table 16

Granger causality between expectations and the data

\begin{tabular}{|c|c|c|c|c|}
\hline \multirow[b]{2}{*}{ Test } & \multicolumn{2}{|c|}{1 lag } & \multicolumn{2}{|c|}{6 lags } \\
\hline & Obs & p-value & Obs & p-value \\
\hline$H_{0}: E_{t}\left(\pi_{t, t+12}\right) \stackrel{G}{\rightrightarrows} \pi_{t}$ & 99 & 0.0943 & 93 & 0.0053 \\
\hline$H_{0}: \pi_{t} \nRightarrow E_{t}\left(\pi_{t, t+6}\right)$ & 99 & 0.0000 & 93 & 0.0034 \\
\hline$H_{0}: E_{t}\left(\Delta i_{t, t+6}\right) \stackrel{g}{\Rightarrow} i_{t}$ & 98 & 0.0004 & 93 & 0.0027 \\
\hline$H_{0}: i_{t} \stackrel{G}{\Rightarrow} E_{t}\left(\Delta i_{t, t+6}\right)$ & 98 & 0.0227 & 93 & 0.0227 \\
\hline$H_{0}: E_{t}\left(\Delta u_{t, t+6}\right) \stackrel{g}{\nRightarrow} u_{t}$ & 99 & 0.0008 & 94 & 0.0000 \\
\hline$H_{0}: u_{t} \stackrel{G}{\nRightarrow} E_{t}\left(\Delta u_{t, t+6}\right)$ & 99 & 0.0574 & 94 & 0.3086 \\
\hline $\begin{array}{l}\text { e } f \text { symbol indicates non- } \\
\text { ies are assumed to be station } \\
\text { ferentiated, since the existen } \\
t \text { this was not the case for in } \\
\text { s were defined based on the } \\
\text { erest. }\end{array}$ & . & he s & 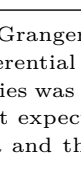 & $\begin{array}{l}\text { Since the } \\
\text { ariable was } \\
\text { tt rejected, } \\
\text { tions. The } \\
\text { horizon of }\end{array}$ \\
\hline
\end{tabular}

\section{A.2 "The consumer inflation target"}

In Figure 1 we saw that consumer inflation forecasts always exceed the realized data, which suggests that the average consumer observes a greater variation in prices 
than the IPCA. To control for this characteristic, we can construct the categorical variable of inflation expectation for the next 12 months by the difference between the forecast and the median of the forecasts. We used the individual median and the monthly median of all individuals. The results of the tests generally remain, with slight modifications. Partial effects have the same results found in Section 3.2. One does not reject the null hypothesis of difference in consistency when considered the periods of deviation by the specifications that analyze the future horizon and the past. For the window deviations, we reject the null hypothesis in the third and fourth windows. Finally, when we consider the two cycles of falling interest rates from 2011, we reject the null for the individual median in both cases, but not for the monthly median.

Table 17

Partial Effects on the Consumer Survey with the median individual forecast

\begin{tabular}{lcc}
\hline \multicolumn{3}{c}{ Partial Effects of Inflation } \\
\hline null hypothesis & mean diff. & p-value \\
$\mathcal{F}(i \uparrow \mid \pi \downarrow, u \downarrow) \geq \mathcal{F}(i \uparrow \mid \pi \uparrow, u \downarrow)$ & -0.0918 & 0.0000 \\
$\mathcal{F}(i \uparrow \mid \pi \downarrow, u \uparrow) \geq \mathcal{F}(i \uparrow \mid \pi \uparrow, u \uparrow)$ & -0.0781 & 0.0000 \\
$\mathcal{F}(i \downarrow \mid \pi \uparrow, u \downarrow) \geq \mathcal{F}(i \downarrow \mid \pi \downarrow, u \downarrow)$ & -0.0683 & 0.0000 \\
$\mathcal{F}(i \downarrow \mid \pi \uparrow, u \uparrow) \geq \mathcal{F}(i \downarrow \mid \pi \downarrow, u \uparrow)$ & -0.0399 & 0.0000 \\
& & \\
\hline \multicolumn{3}{c}{ Partial Effects of Unemployment } \\
\hline null hypothesis & mean diff. & p-value \\
$\mathcal{F}(i \uparrow \mid \pi \downarrow, u \uparrow) \geq \mathcal{F}(i \uparrow \mid \pi \downarrow, u \downarrow)$ & 0.1477 & 1.0000 \\
$\mathcal{F}(i \uparrow \mid \pi \uparrow, u \uparrow) \geq \mathcal{F}(i \uparrow \mid \pi \uparrow, u \downarrow)$ & 0.1340 & 1.0000 \\
$\mathcal{F}(i \downarrow \mid \pi \downarrow, u \downarrow) \geq \mathcal{F}(i \downarrow \mid \pi \downarrow, u \uparrow)$ & 0.0775 & 1.0000 \\
$\mathcal{F}(i \downarrow \mid \pi \uparrow, u \downarrow) \geq \mathcal{F}(i \downarrow \mid \pi \uparrow, u \uparrow)$ & 0.0492 & 1.0000 \\
\hline
\end{tabular}


Table 18

Difference in people's consistency

\begin{tabular}{lccc}
\hline Test & $\# \mathrm{Obs}_{B C=0}$ & mean diff. & p-value \\
\hline Future horizon & & & \\
\cline { 1 - 1 } Median in $t: H_{0}: C_{B C=0} \geq C_{B C=1}$ & 25 & 0.0213 & 0.9633 \\
Median of $i_{t}: H_{0}: C_{B C=0} \geq C_{B C=1}$ & 25 & 0.0486 & 1.0000 \\
Past horizon & & & \\
\cline { 1 - 2 } Median in $t: H_{0}: C_{B C=0} \geq C_{B C=1}$ & 23 & 0.0170 & 0.9166 \\
Median of $i_{t}: H_{0}: C_{B C=0} \geq C_{B C=1}$ & 23 & 0.0378 & 0.9999 \\
\hline \multicolumn{4}{r}{ mean diff. $=\mathrm{C}_{B C=0}-\mathrm{C}_{B C=1}$} \\
\end{tabular}

Table 19

Difference in people's consistency

\begin{tabular}{|c|c|c|c|}
\hline Test & $\# \operatorname{Obs}_{B C=0}$ & mean diff. & p-value \\
\hline \multicolumn{4}{|l|}{ 1st window } \\
\hline Median in $t: H_{0}: C_{B C=0} \geq C_{B C=1}$ & 40 & 0.0460 & 1.0000 \\
\hline Median of $i_{t}: H_{0}: C_{B C=0} \geq C_{B C=1}$ & 40 & 0.0242 & 0.9974 \\
\hline \multicolumn{4}{|l|}{ 2nd window } \\
\hline Median in $t: H_{0}: C_{B C=0} \geq C_{B C=1}$ & 40 & 0.0114 & 0.8600 \\
\hline Median of $i_{t}: H_{0}: C_{B C=0} \geq C_{B C=1}$ & 40 & 0.0257 & 0.9986 \\
\hline \multicolumn{4}{|l|}{ 3rd window } \\
\hline Median in $t: H_{0}: C_{B C=0} \geq C_{B C=1}$ & 40 & -0.0179 & 0.0445 \\
\hline Median of $i_{t}: H_{0}: C_{B C=0} \geq C_{B C=1}$ & 40 & -0.0345 & 0.0000 \\
\hline \multicolumn{4}{|l|}{ 4th window } \\
\hline Median in $t: H_{0}: C_{B C=0} \geq C_{B C=1}$ & 40 & -0.0416 & 0.0000 \\
\hline Median of $i_{t}: H_{0}: C_{B C=0} \geq C_{B C=1}$ & 40 & -0.0220 & 0.0055 \\
\hline
\end{tabular}


Table 20

Difference in people's consistency

\begin{tabular}{|c|c|c|c|}
\hline Test & $\# \mathrm{Obs}_{B C=0}$ & mean diff. & $\mathrm{p}$-value \\
\hline \multicolumn{4}{|l|}{ Aug. 2011 to Oct. 2012: } \\
\hline Median in $t: H_{0}: C_{B C=0} \geq C_{B C=1}$ & 15 & -0.0113 & 0.2184 \\
\hline Median of $i_{t}: H_{0}: C_{B C=0} \geq C_{B C=1}$ & 15 & -0.0336 & 0.0023 \\
\hline \multicolumn{4}{|l|}{ Aug. 2011 to Mar. 2013: } \\
\hline Median in $t: H_{0}: C_{B C=0} \geq C_{B C=1}$ & 20 & -0.0025 & 0.4244 \\
\hline Median of $i_{t}: H_{0}: C_{B C=0} \geq C_{B C=1}$ & 20 & -0.0201 & 0.0304 \\
\hline
\end{tabular}

\section{A.3 Consistency tests with alternative specifications}

Table 21

Difference in people's consistency

\begin{tabular}{|c|c|c|c|}
\hline Test & $\# \mathrm{Obs}_{B C=0}$ & mean diff. & $\mathrm{p}$-value \\
\hline \multicolumn{4}{|l|}{ Future horizon } \\
\hline Specification 1: $H_{0}: C_{B C=0} \geq C_{B C=1}$ & 24 & -0.0341 & 0.0314 \\
\hline Specification 2: $H_{0}: C_{B C=0} \geq C_{B C=1}$ & 24 & -0.0599 & 0.0042 \\
\hline \multicolumn{4}{|l|}{ Past horizon } \\
\hline Specification 1: $H_{0}: C_{B C=0} \geq C_{B C=1}$ & 23 & 0.0174 & 0.8236 \\
\hline Specification 2: $H_{0}: C_{B C=0} \geq C_{B C=1}$ & 23 & -0.0012 & 0.4804 \\
\hline
\end{tabular}


Table 22

Difference in people's consistency

\begin{tabular}{|c|c|c|c|}
\hline Test & $\# \mathrm{Obs}_{B C=0}$ & mean diff. & p-value \\
\hline \multicolumn{4}{|l|}{ 1st window } \\
\hline Specification 1: $H_{0}: C_{B C=0} \geq C_{B C=1}$ & 40 & -0.0487 & 0.0010 \\
\hline Specification 2: $H_{0}: C_{B C=0} \geq C_{B C=1}$ & 40 & -0.0592 & 0.0013 \\
\hline \multicolumn{4}{|l|}{ 2nd window } \\
\hline Specification 1: $H_{0}: C_{B C=0} \geq C_{B C=1}$ & 40 & 0.0083 & 0.6955 \\
\hline Specification 2: $H_{0}: C_{B C=0} \geq C_{B C=1}$ & 40 & -0.0058 & 0.3872 \\
\hline \multicolumn{4}{|l|}{ 3rd window } \\
\hline Specification 1: $H_{0}: C_{B C=0} \geq C_{B C=1}$ & 40 & 0.0159 & 0.8378 \\
\hline Specification 2: $H_{0}: C_{B C=0} \geq C_{B C=1}$ & 40 & 0.0219 & 0.8618 \\
\hline \multicolumn{4}{|l|}{ 4th window } \\
\hline Specification 1: $H_{0}: C_{B C=0} \geq C_{B C=1}$ & 40 & 0.0488 & 0.9990 \\
\hline Specification 2: $H_{0}: C_{B C=0} \geq C_{B C=1}$ & 40 & 0.0606 & 0.9990 \\
\hline
\end{tabular}

Table 23

Difference in people's consistency

\begin{tabular}{|c|c|c|c|}
\hline Test & $\# \mathrm{Obs}_{B C=0}$ & mean diff. & p-value \\
\hline \multicolumn{4}{|l|}{ Aug. 2011 to Oct. 2012: } \\
\hline Specification 1: $H_{0}: C_{B C=0} \geq C_{B C=1}$ & 15 & -0.0326 & 0.0693 \\
\hline Specification 2: $H_{0}: C_{B C=0} \geq C_{B C=1}$ & 15 & -0.0389 & 0.0786 \\
\hline \multicolumn{4}{|l|}{ Aug. 2011 to Mar. 2013: } \\
\hline Specification 1: $H_{0}: C_{B C=0} \geq C_{B C=1}$ & 20 & -0.0350 & 0.0370 \\
\hline Specification 2: $H_{0}: C_{B C=0} \geq C_{B C=1}$ & 20 & -0.0471 & 0.0270 \\
\hline
\end{tabular}

